\title{
O CONTEXTO INCLUSIVO NA ESCOLA: REPRESENTAÇÃO E ESTIGMA NA PERSPECTIVA DE DUAS PROFESSORAS
}

\section{THE CONTEXT OF SCHOOL INCLUSION: SOCIAL REPRESENTATION AND STIGMA VIEWED FROM THE PERSPECTIVE OF TWO TEACHERS}

\author{
DOI: $\underline{\text { http://dx.doi.org/10.5965/1984317815022019168 }}$ \\ Regina Finck Schambeck \\ Universidade do Estado de Santa Catarina \\ regina.finck@udesc.br
}

\begin{abstract}
RESUMO:
Este artigo está relacionado à representação sobre o contexto inclusivo na escola sob a perspectivas de duas professoras que atuam no ensino fundamental. Traz reflexões sobre o contexto inclusivo e a inserção de alunos com deficiência, a partir de questionários abertos aplicados para as professoras, que contemplou categorias, a saber: o perfil das profissionais, práticas pedagógicas, experiências profissionais com inclusão e preconceito, estigma e representação na escola. Também fizeram parte do roteiro questões sobre as relações da criança com deficiência com os seus colegas, com as professoras, com a escola e com os pais. A partir da contextualização das práticas dessas professoras, foi realizada uma aproximação das suas falas, analisando-as e relacionando-as com as discussões teóricas sobre representação social e estigma. Foi possível identificar que, nos contextos investigados, ficou evidenciado que as práticas de sala de aula dessas professoras buscavam incluir os alunos, mas, ainda, apesar dos esforços empreendidos, persistiu nas unidades escolares uma cultura na qual não se pode eliminar todos os preconceitos ou convenções presentes na sociedade, inclusive aqueles que pressupõem que alunos com deficiência intelectual pouco poderão aprender no espaço educativo.
\end{abstract}

Palavras-chave: Contexto inclusivo. Educação especial. Representação Social. Estigma.

ABSTRACT: This article examines the social representation of school inclusion as viewed from the standpoint of two female teachers in basic education. It examines the inclusive background and extent to which students with impairments are incorporated in the school, on the basis of open-ended questionnaires that were completed by the teachers. These included the following areas, namely: the profile of the professionals, pedagogical practices, their professional experience of inclusion, as well as the nature of the social representation, prejudices and stigma found in schools. The questions centred on issues regarding the relations handicapped children had with their colleagues, the teachers, the school itself and the parents. By putting these teachers' practices into context, it was possible to obtain an approximate idea of their comments and conduct an analysis that linked them to theoretical discussions. As a result, evidence was found that, in the area under investigation, the teachers sought to include the students through their practices. However, despite the measures that were taken, there still lingered on a culture in the school departments where not all the prejudices and conventional attitudes found in society could be dispelled, including assume that students with intellectual impairments can learn very little in educational spaces.

Keywords: inclusive context. Specialist education. Social representation. Stigma. 


\section{INTRODUÇÃO}

Este artigo tem por objetivo discutir práticas de inclusão, envolvendo os pressupostos teóricos de representação social (MOSCOVICI, 1978, 2011) e estigma (GOFFMAN, 1988), a partir da análise da experiência de duas professoras que atuam em escolas de educação básica, em contexto de inclusão. Pretende-se estabelecer a relação entre educação musical e educação especial a partir de ações metodológicas alternativas para ação pedagógica do professor de música em contexto inclusivo e de adaptação de atividades musicais para o desenvolvimento de potencialidades musicais de alunos com deficiência.

O objetivo deste artigo é compreender o contexto inclusivo de escolas da educação básica a partir da perspectiva de duas professoras que atuam nesses espaços educativos, tendo por base os pressupostos teóricos da representação social e estigma. Em diferentes momentos da história da humanidade, o estigma sempre foi caracterizado por ser um estranhamento inicial que acaba por acarretar uma série de percepções negativas e equivocadas aos indivíduos.

O psicólogo social Serge Moscovici foi o criador do termo representações sociais, utilizando-o para nomear "uma modalidade de conhecimento particular que tem por função a elaboração de comportamentos e a comunicação entre indivíduos" (MOSCOVICI, 1978, p. 26). Segundo o autor, todas as interações humanas pressupõem representações, as quais possuem duas funções básicas: convencionalizar objetos, pessoas ou acontecimentos, classificando-os em categorias, e prescrever representações, mesmo antes de se conhecer os modelos a serem seguidos. Essas representações se impõem sobre nós com uma força irresistível, pois, ao avaliar alguém e, por consequência, rotular essa pessoa, estaríamos "revelando a nossa 'teoria' da sociedade e da natureza humana” (MOSCOVICI, 2011, p. 62). Moscovici esclarece que nenhuma mente está livre dos efeitos de condicionamentos anteriores impostos por representações, linguagem ou cultura e, mesmo com esforços, não se pode eliminar todos os preconceitos ou convenções presentes na sociedade na 
qual vivemos, pois, "antes de ver e ouvir a pessoa, nós já julgamos; nós já a classificamos e criamos uma imagem dela" (MOSCOVICI, 2011, p. 58).

Ao afirmar que "o pensamento social deve mais à convenção e à memória do que à razão; deve mais às estruturas tradicionais do que às estruturas intelectuais ou perceptivas correntes", Moscovici compartilha o importante papel da ciência na mudança de paradigmas, ou seja, para superar nossa tendência de confirmar o que é familiar, para provar o que já é conhecido, o cientista "deve falsificar, deve tentar invalidar suas próprias teorias e confrontar a evidência com a não evidência [...], o objetivo da ciência é tornar o familiar não familiar" (MOSCOVICI, 2011, p. 59-60). Deste modo, ao nos referirmos ao conceito de representação social, seria preciso rever e repensar, constantemente, a maioria de nossas percepções e opiniões correntes. $\mathrm{Na}$ tentativa de se quebrar o senso comum "a ciência era antes baseada no senso comum e fazia o senso comum menos comum; mas agora senso comum é a ciência tornada comum" (MOSCOVICl, 2011, p. 59-60), reforçando, assim, o papel da ciência na sociedade atual em "gerar agora as representações sociais que devem ser transferidas a um mundo consensual, circunscrito e re-apresentado" (MOSCOVICI, 2011, p. 60).

Ervin Goffman, por sua vez, nos apresenta ao conceito de estigma, entendido como um produto da aprendizagem, e é na interação social onde se dá, geralmente, a estimulação ou a iniciação do processo de aprendizagem social:

Enquanto o estranho está à nossa frente, podem surgir evidências de que ele tem um atributo que o torna diferente de outros que se encontram numa categoria em que pudesse ser incluído, sendo, até, de uma espécie menos desejável [...]. Assim deixamos de considerá-la criatura comum e total, reduzindo-a a uma pessoa estragada e diminuída. Tal característica é estigma, especialmente quando o seu efeito de descrédito é muito grande [...]. (GOFFMAN, 1988, p. 12).

A primeira noção que se tem de uma pessoa começa, principalmente, a partir dessas evidências ou atributos destacados pelo autor, fruto de um contato inicial, ou seja, das características gerais daquele indivíduo, como por exemplo: de onde vem, etnia, fisionomia, grau de instrução, ascensão social, nível intelectual, orientação 
sexual, o modo como se veste etc. Segundo Goffmann (1985), quando classificamos uma pessoa, é porque estamos buscando naquela pessoa uma proximidade ou identificação daquilo que seria considerado como "normal" para aquele contexto social. O conceito de normalidade, nessa perspectiva, varia de acordo com as experiências e os contextos vivenciados por cada indivíduo, em particular.

Conforme descrito acima, seria, de fato, a primeira impressão de alguém aquela que realmente fica na nossa percepção? Porém, segundo o autor, a primeira presença, gerada pelo contato imediato frente aos indivíduos, não seria suficiente para que se obtivesse informações conclusivas, isto porque muitos fatos decisivos estão além do tempo e do lugar de interação, ou seja, "aquilo que o indivíduo transparece ser nem sempre é aquilo que ele realmente é" (GOFFMAN, 1988, p. 12).

Moscovici (2011), também destaca a importância das trocas sociais para a formação do conceito de representação social. Para ele, todas as nossas percepções, ideias e atribuições sobre o mundo são respostas a estímulos do ambiente físico em que vivemos. Nossas reações aos acontecimentos estão relacionadas a funções comuns a membros da comunidade à qual pertencemos. Buscamos, então, representações que sejam semelhantes ou exatamente iguais às nossas próprias. Entretanto, qual a função destas representações? Moscovici (2011) nos diz que as representações possuem duas funções: a primeira é que elas convencionalizam objetos, pessoas ou acontecimentos, dando uma forma definitiva, categorizando e colocando um modelo determinado e partilhado por um grupo de pessoas; a segunda é que elas são prescritivas e se impõem sobre nós com uma força irresistível.

Porém, num mundo composto por pessoas de culturas, cores, raças e sexos diferentes, não é possível que se espere que todas as pessoas compartilhem das mesmas representações sociais. Para Goffman (2008), ao estigmatizar alguém, estaríamos confirmando que há uma "normalidade" de outrem. Em seu livro Estigma: notas sobre a manipulação da identidade deteriorada (2008), o autor explicita que o próprio indivíduo, que estigmatiza, pode também carregar em si um estigma: 
Parece também possível que um indivíduo não consiga viver de acordo com o que foi efetivamente exigido dele e, ainda assim, permanecer relativamente indiferente ao seu fracasso; isolado por sua alienação, protegido por crenças de identidade próprias, ele sente que é um ser humano completamente normal e que nós é que não somos suficientemente humanos. Ele carrega um estigma, mas não parece impressionado ou arrependido por fazê-lo. (GOFFMAN, 2008, p. 16).

Sendo assim, ao estigmatizar uma pessoa, nos esquecemos que nós mesmos podemos ser estigmatizados. Segundo Goffman (2008), há três tipos de estigma:

Tabela 1 - Tipologia de estigma

1) O estigma quanto às "abominações do corpo" - quando há uma "deformidade física";

2) O estigma quanto ao caráter individual - que compreende paixões tirânicas ou "não naturais", crenças falsas e rígidas, "sendo essas inferidas a partir de relatos de, por exemplo, distúrbio mental, prisão, vício, alcoolismo, homossexualidade, desemprego, tentativas de suicídio e comportamento político radical” (p. 14);

3) Estigmas tribais da raça, nação e religião - que podem ser transmitidos através da linhagem familiar.

Fonte: Elaborado pela autora com base em Goffmann (2008)

Estigmatizar é, por vezes, colocar pessoas em "caixas" e ignorar que suas diferenças tendem a acrescentar às nossas experiências e que a nossa realidade não é pior nem melhor que a realidade do outro. Pessoas com deficiência lutam por acessibilidade, para serem reconhecidas pelas suas capacidades, e não por suas deficiências.

\section{ENFOQUE METODOLÓGICO}

A partir dos pressupostos teóricos de representação social (MOSCOVICI, 1978, 2011) e estigma (GOFFMAN, 1988, 2008), buscou-se compreender como professoras atuam em escolas inclusivas e as práticas de ensino por elas adotadas. Pretende-se 
estabelecer a relação entre a educação musical e a educação especial, a partir de ações metodológicas alternativas para ação pedagógica do professor de música em contexto inclusivo e a adaptação de atividades musicais para o desenvolvimento de potencialidades musicais de alunos com deficiência.

A estrutura metodológica adotada pautou-se na aplicação de questionário, adotado como instrumento de coleta de dados. Segundo Gil (2008), o questionário é utilizado em pesquisas "com o propósito de obter informações sobre conhecimentos, crenças, sentimentos, valores, interesses, expectativas, aspirações, temores, comportamento presente ou passado" (GIL, 2008, p. 121).

Para responder à questão de pesquisa e contemplar o objetivo geral, fez-se necessário obter informações mais específicas sobre aspectos das práticas profissionais. Para tal, foram dispostos, no roteiro de questões, temas como: a participação e avaliação nos conteúdos curriculares básicos, específicos e teóricopráticos; a oferta de apoio pedagógico curricular, as relações interpessoais e a promoção de acessibilidade. Uma aproximação mais detalhada sobre esses aspectos e processos tornou possível contemplar, com mais clareza, a perspectiva educacional na visão do professor que atua em contexto inclusivo, evidenciando o modo como esta inserção ocorre, criando, assim, um espaço de reflexão do processo de educação para alunos e professores

[...] sob a ótica do indivíduo e das coletividades, os quatro referenciais básicos da bioética: autonomia, não maleficência, beneficência, justiça e equidade, dentre outros, e visa assegurar os direitos e deveres que dizem respeito aos participantes da pesquisa, à comunidade científica e ao Estado. (BRASIL, 2012, p. 1).

Os critérios éticos adotados foram pautados nos princípios indicados por Gray (2012), que sugerem riscos mínimos aos participantes, não envolvendo procedimentos invasivos e identidades e contextos de atuação preservados.

Foi decidido pela utilização dos codinomes Amanda e Berenice para as professoras participantes. A professora Amanda respondeu seu questionário através do 
e-mail, já a professora Berenice preferiu enviar um vídeo feito por ela mesma, contendo as falas sobre o objeto da pesquisa. Esse vídeo foi posteriormente transcrito. Mesmo pertencendo a contextos de trabalhos diferentes as duas professores apresentam como pontos em comum a atuação em contexto inclusivo na educação básica. Portanto, os aspectos das práticas profissionais foram identificados e reforçados nas falas das duas professoras nesse recorte da pesquisa. Em relação à forma do instrumento de coleta de dados, optou-se por utilizar o questionário com perguntas abertas, "que permitem ao informante responder livremente, usando linguagem própria, e emitir opiniões" (MARCONI; LAKATOS, 2010, p. 89).

O questionário aberto permitiu a cada uma das professoras a liberdade para aprofundar ou não as quatro temáticas, objeto da investigação: a primeira possuía questões de ordem pessoal, sobre a formação de cada professora e a motivação para trabalhar em contexto escolar inclusivo. A segunda possuía questões sobre a perspectiva de cada uma das professoras sobre a inclusão, e a terceira parte focava nas experiências profissionais com inclusão, descrição das escolas onde atuavam, características da classe, recursos oferecidos para o trabalho em contexto inclusivo e questões relacionadas às atividades em sala de aula. A quarta seção de perguntas envolvia a temática preconceito, estigma e representação dos alunos com deficiência na escola em que as professoras atuavam. Também fizeram parte questões sobre as relações da criança com deficiência com os seus colegas, com as professoras, com a escola e com os pais.

É importante destacar que as duas professoras atuam em diferentes contextos. A professora Amanda ministra aulas de Música para um pequeno grupo de alunos de uma escola básica em um projeto extracurricular, e a professora Berenice atua em uma turma regular também da educação básica. 


\section{SOBRE AS PARTICIPANTES DA PESQUISA}

\section{Professora Amanda}

Reside em município localizado na região norte catarinense e tem trabalhado com música há mais de 20 anos. Como formação acadêmica, a professora fez o curso de Bacharelado em Musicoterapia na Faculdade de Artes do Paraná (FAP), que faz parte atualmente da Universidade Estadual do Paraná (Unespar), no campus de Curitiba II. A professora também é pós-graduada em Fundamentos do Ensino da Arte e Orientação Pedagógica.

Trabalha em uma escola municipal oportunizando atividades musicais com violino para dez alunos da unidade, em forma de oficina. São alunos do nono ano, com aproximadamente 16 e 17 anos de idade. Dentre os participantes da oficina, um aluno com diagnóstico de deficiência intelectual está incluído. As atividades ocorrem no contraturno em que os jovens participantes estudam, caracterizando a oficina de música como atividade extracurricular.

\section{Professora Berenice}

A professora Berenice reside e trabalha em um município da Grande Florianópolis. É formada em Pedagogia pela Uniasselvi (instituição de ensino superior mantida pela Associação Educacional Leonardo da Vinci). Na época da pesquisa, fazia um curso de Letras-Libras na Universidade Federal de Santa Catarina (UFSC). Tem participado de cursos oferecidos pela Fundação Catarinense de Educação Especial que são direcionados para professores do estado de Santa Catarina, bem como cursos oferecidos por outras instituições direcionados ao trabalho pedagógico com diferentes deficiências. 
Berenice trabalha como "segundo professor", em um colégio estadual e atende um aluno com diagnóstico de deficiência intelectual. A inserção do trabalho de um "segundo professor" na sala de aula é regida pela Resolução Estadual n 112 (SANTA CATARINA, 2006) e, mais recentemente, a Lei $n^{\circ}$ 17.143, de 15 de maio de $2017^{1}$ e tem por objetivo a valorização da educação especial e a proteção de direitos aos estudantes com deficiência.

O menino atendido tem 12 anos e frequenta a turma do quinto ano, que é composta por 30 alunos com idade média entre 11 e 12 anos. Porém, nessa sala há também alunos com até 16 anos de idade. A professora Berenice comenta que em anos anteriores já trabalhou, como "segundo professor", em turmas de alunos com diagnósticos de outras deficiências. Ela já atendeu um aluno autista, um aluno com deficiência intelectual leve e um aluno autista com cegueira.

\section{REFLEXÕES SOBRE O TRABALHO EM CONTEXTO INCLUSIVO}

\section{Professora Amanda}

Quando questionada sobre sua motivação para trabalhar em contexto inclusivo, a professora Amanda falou sobre a sua formação em Musicoterapia, etapa considerada muito importante para que se sentisse preparada para atuar nesse tipo de contexto. $O$ aluno incluído sempre demonstrou gostar das atividades musicais, por isso participa das aulas de violino dessa professora. A relação entre aluno e professora também é positiva, de respeito e afeto mútuo, questão que também proporciona um ambiente

\footnotetext{
${ }^{1}$ A Lei no 17.143 , de 15 de maio de 2017, é de autoria da deputada estadual Luciane Carminatti e tem como objetivo central a valorização da educação especial e a proteção de direitos aos estudantes com deficiência. A lei obriga a presença do segundo professor nas salas de aula que tiverem alunos com diagnóstico de: a) deficiência múltipla associada à deficiência mental; b) deficiência mental que apresente dependência em atividades de vida prática; c) deficiência associada a transtorno psiquiátrico; d) deficiência motora ou física com sérios comprometimentos motores e dependência de vida prática; e)Transtorno do Espectro do Autismo com sintomatologia exacerbada; e g) Transtorno de Déficit de Atenção com Hiperatividade/impulsividade com sintomatologia exacerbada.
} 
propício para as aulas de música, fazendo com que o aluno participe das atividades e tenha contato com o instrumento musical.

Sobre o conceito de inclusão no contexto escolar, a professora Amanda acredita ser uma maneira de "aprender a respeitar as diferenças", porém não vê vantagem em determinadas pessoas com deficiências participarem do ambiente escolar, pois infelizmente podem vir a não acompanhar o conteúdo. A professora relata:

PA: Acredito que se o investimento feito na escola regular fosse feito para escolas especiais, teríamos muito mais resultados para o aluno, possibilitando a contratação de mais profissionais de diversas áreas, estimulando corretamente o seu amplo desenvolvimento. (Professora Amanda, excerto do questionário)

O texto da professora reflete a perspectiva da sua formação (formada em Musicoterapia). Segundo ela, as crianças com deficiência são estimuladas a participar também de atividades em escolas especiais e em outras instituições, além da escola regular. Para a professora, a participação ativa também em outros espaços formativos possibilita o desenvolvimento e a melhoria da comunicação; oportuniza um suporte emocional; facilita a aprendizagem, pois os trabalhos desenvolvidos são direcionados para as necessidades específicas de atendimento; provê a autonomia e o desenvolvimento biopsicossocial das pessoas. Mesmo acreditando que a inclusão de alunos com deficiências em ambiente escolar não é uma vantagem para o aluno, o caso relatado do seu aluno com deficiência intelectual que participa das aulas de violino pode ser visto como um caso positivo de inclusão escolar nas aulas de música.

Amanda afirma que um ambiente escolar seria inclusivo se todos respeitassem as condições de aprendizagem dos alunos. Moscovici (2011), ao abordar as representações sociais de grupos heterogêneos, reforça que a melhor estratégia para evitar preconceitos é reconhecer que as representações constituem apenas uma realidade, logo, cada pessoa vive uma realidade diferente. Ao respeitarmos essas diferenças, sem impor nossa própria ideologia, contribuímos para que a inclusão ocorra, independentemente do espaço onde ela ocorre. 
A professora descreve que nas suas aulas o aluno com deficiência é bem recebido por ela e por seus colegas, que existe um relacionamento tranquilo; inclusive, pelo seu ponto de vista, é fundamental a interação dele com a turma, que o ajuda em diversos momentos das aulas. Questionada sobre os recursos que a escola oferece para auxiliar o trabalho no contexto inclusivo, ela relata o acompanhamento de uma professora "extra". O professor extra a que a professora Amanda se refere é o "segundo professor".

Além do apoio do segundo professor, Amanda também destaca como fator importante para a inclusão a disponibilidade de instrumentos musicais (no caso, violinos), que foram adquiridos pela escola. Outro fator propício para a inclusão, mencionado pela professora, é o ambiente de muito respeito entre todos os envolvidos: "Existe um trabalho com a turma e com os professores para o esclarecimento dessas questões, mas este é feito anteriormente à minha aula". Quando questionada sobre a família do aluno, a professora descreve essa relação como "complicada", pois afirma, taxativamente, que "a mãe não se interessa pelas atividades escolares do filho". Com relação à falta de interesse da mãe pelas atividades do seu filho na escola, pode-se inferir, o impacto que as representações convencionalizadas socialmente por um grande número de pessoas na forma como ela percebe o seu filho com deficiência. Como nos orienta Moscovici (2011), ao categorizar como incapaz e colocar esse indivíduo sob o jugo de um modelo determinado e partilhado coletivamente, influencia definitivamente nas concepções de inclusão e se impõe de sobremaneira nessa mãe. Porém, mesmo diante da relação complicada com a unidade escolar, a mãe permite que o adolescente frequente as aulas de música, o que de certa maneira surpreende a professora.

É possível perceber que a professora Amanda acredita que a inclusão em ambiente escolar ainda é uma questão a ser amplamente discutida para que sejam encontradas formas e alternativas para que o aluno com deficiência tenha a possibilidade de acompanhar o conteúdo e todo o desenvolvimento da turma na escola. Esse é um tema que a preocupa verdadeiramente e é mencionado por ela várias 
vezes, conforme análise do material transcrito. Por fim, a professora relata que a inclusão "não deve ser apenas algo que funciona no papel, mas, sim, algo que faça sentido àquele que mais interessa: o aluno incluso". E isso é visível no caso do aluno com a deficiência com o qual mantém contato mais próximo.

\section{Professora Berenice}

Questionada sobre a motivação para trabalhar com crianças deficientes, a professora Berenice relata que, durante a faculdade de Pedagogia, começou a ter uma "outra visão" sobre as deficiências e a se questionar como seria trabalhar com estes alunos, sem preconceitos. Ela comenta que é o que busca em seu trabalho, ou seja, não ter preconceitos com as crianças com deficiência. Por isso, procura diversificar as deficiências que atende para que em cada ano de trabalho tenha uma experiência nova, além de proporcionar um desenvolvimento para o aluno que ficará sob seu direcionamento pedagógico. Ela relata que o aluno que atendeu no ano anterior, autista e cego, participava de todas as atividades com as outras crianças, "até pular corda nas aulas de educação física a gente fazia, era uma atividade que ele achava que não poderia participar". Podemos perceber o comprometimento profissional desta professora, que vai de encontro com o "gostar" de atuar como professora de alunos com deficiência. Ela cita outro profissional, o professor de educação física daquela escola, que também é engajado na questão da inclusão e que, por isso, estabeleceu uma parceria com ele. Segundo Berenice, ele procurava "adaptar os jogos para que o aluno com deficiência intelectual pudesse sempre estar incluído nas atividades".

Em relação ao assunto da inclusão em contexto escolar, a professora Berenice avalia que "poderia ser melhor". Segundo ela, deveria haver uma maior preocupação com o contexto "em geral da escola, não só com os professores e alunos que estão diretamente ligados ao aluno com deficiência, mas uma preparação geral da escola". Berenice relata que percebe que até mesmo "outros professores da escola não estão preparados para lidar com alunos deficientes". Ela considera que se pensar realmente na inclusão, como deveria acontecer, o sistema é "totalmente falho". 
A escola onde atua a professora Berenice, localizada na grande Florianópolis, dispõe de uma psicopedagoga que orienta os professores, os alunos e as famílias das crianças com deficiência. Este aluno com deficiência já está inserido no contexto desta escola desde o primeiro ano do ensino fundamental, portanto há cinco anos ele frequenta a escola e tem acompanhamento da psicopedagoga. Mesmo assim, a professora relata as dificuldades encontradas em relação à inclusão desta criança no ambiente escolar: "[...] a mãe da criança com deficiência não entendia por que o filho ainda não havia aprendido a ler". Berenice conta que precisou ter uma conversa com a mãe da criança, esclarecendo a realidade da situação de aprendizagem de seu filho, que, sim, naquele momento ele não conseguiria ler, mas que estava sendo feito um trabalho para que ele tivesse avanços em outras áreas do desenvolvimento. Ela reforça em seu depoimento que muitas vezes a própria família não aceita as diferenças de aprendizagem que a criança possui. "Sabemos que é evidente que os pais esperam resultados e temos certeza de que eles acontecem, porém não são como o desenvolvimento de outras crianças". Depois desta conversa com a mãe da criança com deficiência, que aconteceu no início do ano letivo, a professora Berenice relata que, mesmo antes do fim ano, a mãe, e até os outros professores da escola, já percebiam grande diferença no desenvolvimento deste aluno. Neste momento, Berenice enfatiza a questão do "gostar". Para ela, o gosto pelo que se faz é muito importante: "Quando você faz o que gosta, a coisa acontece". Mas fica evidente, na sua fala, que os alunos deficientes dependem da boa vontade de todos os profissionais da escola.

Sobre a questão do estigma e das representações sociais da criança com deficiência, Berenice comenta que "às vezes a gente ouve alguns murmúrios dos próprios colegas [...]" -referindo-se aos colegas professores - e destaca, também, que "há ciúmes entre as crianças", e justifica que isso acontece porque ela fica exclusivamente com o aluno com deficiência intelectual e os outros alunos da classe também querem uma "atenção exclusiva". 
Na escola em que a professora Berenice atua não há atividades musicais nas aulas de Artes, porém esta professora comenta que considera muito importante a educação musical escolar, pois inclui os tipos de música que as crianças gostam. Ela acredita que, se houvesse música na escola, as crianças conseguiriam pensar mais sobre as músicas que escutam e, desta forma, "não teria tanta música ruim como se tem hoje". Segundo a professora, a música na escola poderia "trabalhar um todo, não só a questão do bom gosto pela música, mas no geral”.

A professora Berenice considera a questão da inclusão de alunos com deficiências na escola um assunto que ainda demanda muita discussão, e considera "que todo o sistema teria que se modificado". Contudo, não aprofunda o que considera necessário modificar no sistema para que a inclusão ocorra.

\section{ANÁLISE DOS DADOS}

Percebemos na professora Amanda, desde a sua formação inicial em Musicoterapia, a motivação em trabalhar com alunos deficientes. Já a professora Berenice cursou Pedagogia e durante o curso começou a pensar nesta possibilidade, buscando na segunda graduação um aperfeiçoamento para sua prática pedagógica. Apesar de terem tido contato com alunos deficientes por caminhos diferentes, percebemos na fala das duas professoras a satisfação e o engajamento que possuem no trabalho em contexto inclusivo. No trabalho delas é possível perceber que "o que muda é a conceitualização desse aluno, dependendo de quem está 'observando'”. E a maneira como um professor "define um estudante com deficiência tem tudo a ver com o resultado educacional daquele estudante" (VALLE; CONNOR, 2014, p. 35). Elas acreditam no potencial de desenvolvimento de seus alunos, fazendo com que as deficiências não sejam fatores limitantes para a evolução no processo de educação.

Sobre a questão da inclusão dos alunos deficientes no contexto escolar, percebemos que tanto a professora Amanda quanto a professora Berenice acreditam nesta possibilidade. Elas observam, porém, que devem acontecer adaptações para que 
a inclusão efetivamente aconteça. A professora Amanda vê a inclusão como uma forma de "aceitar as diferenças", porém acredita que a mesma seria mais eficaz em um "contexto de escolas especiais". Apesar de não se opor à inclusão no contexto escolar, a professora aponta que o investimento feito em um "segundo professor" para um único aluno poderia ser aproveitado por uma quantidade maior de alunos em escolas especiais. Já a professora Berenice considera que a escola é um "ambiente propício para a inclusão", mas acredita que mudanças teriam que acontecer para que ela ocorresse de fato.

Segundo o Index (SANTOS, 2002, p.7), inclusão envolve mudanças. "É um processo infindável de aumento da aprendizagem e da participação de todos os estudantes [...], uma escola inclusiva é aquela que está em movimento". O Index, portanto, é um "conjunto de materiais", como definem Booth e Ainscow (apud SANTOS, 2002, p. 7), com a potencialidade de "apoiar um processo de autorrevisão das escolas em direção à ampliação da aprendizagem e da participação dos sujeitos nela inseridos" (idem).

Esse processo de autorrevisão de postura está em consonância com as opiniões das professoras entrevistadas. A professora Amanda considera a inclusão como "o respeito às diferenças". Por outro lado, a professora Berenice se refere às mudanças estruturais na unidade escolar que deveriam ocorrer para que a "inclusão acontecesse de fato".

Segundo Santos (2002), a estrutura do Index é composta por uma parte teóricoconceitual que, além de explicitar o conceito de inclusão, propõe valores a serem desenvolvidos nas escolas. A parte prática se encontra dividida em três dimensões: a construção de culturas na escola, o desenvolvimento de políticas e, por fim, a organização de práticas de inclusão. A dimensão de culturas diz respeito aos valores e crenças compartilhados que orientam as políticas e as práticas. A dimensão das políticas refere-se aos acordos, às intenções e planejamentos, mesmo aqueles que estão subjacentes e que estimulam e/ou medeiam as ações. A dimensão das práticas, por sua vez, dialoga com as próprias ações em prol da minimização de barreiras à 
aprendizagem e à participação. Santos (2002) finaliza esclarecendo que as dimensões estão sempre em diálogo e perpassam umas às outras. Por mais que o material esteja dividido nessas três seções, em cada uma, tanto culturas, políticas e práticas podem ser percebidas.

Cumpre assinalar, ainda, que inclusão no referido instrumento é concebida como "processo incessante voltado para o envolvimento de indivíduos, a criação de sistemas e ambientações participativos e a promoção de valores inclusivos" (BOOTH; AINSCOW, 2011, apud SANTOS et al., 2017, p. 2). Para os autores, a inclusão em educação, portanto, envolve colocar valores em ação de modo a minimizar exclusões e/ou barreiras à aprendizagem e à participação de todo e qualquer indivíduo, valorizando-o diante da diversidade.

Com relação ao uso do Index, Santos et al. (2014, p. 492) nos alertam que se: o Index for utilizado como um instrumento que simplesmente "se aplica" a dado contexto, seu potencial de promover a participação ficaria perdido. Para a autora a ideia do Index é a de que ele seja desenvolvido em um processo na escola, e não aplicado como um instrumento de avaliação.

Sabemos da legislação vigente sobre a inclusão e de muitas iniciativas que vêm sendo tomadas pelo poder público em relação a este assunto. Porém, percebemos nas falas das duas professoras que este processo ainda depende muito dos professores envolvidos. Em relação a isso, Valle e Connor (2014) afirmam que:

O fato de a lei ser ou não cumprida depende de professores comprometidos com os ideais da educação pública em uma democracia. Assim, aquilo no que você acredita e por que acredita tem tudo a ver com quem você é como professor. E quem você é como professor tem tudo a ver com o que você pensa e como ensina as crianças. (VALLE; CONNOR, 2014, p. 34-35).

Tal comprometimento dos professores faz toda a diferença dentro do ambiente escolar, pois a inclusão é praticada de momento a momento nas interações que acontecem entre professores e alunos (VALLE; CONNOR, 2014, p. 91). Um ambiente 
não receptivo para os alunos incluídos pode gerar uma interpretação estigmatizada deles.

Ao se referir ao aluno com surdez, Haguiara-Cervellini (2003, p. 59) exemplifica o papel da representação social e da sua força para estigmatizar uma pessoa. Para ela, quando a surdez é diagnosticada, o senso comum traz a representação do surdo como aquele que não escuta. Essa representação seria imediatamente assumida pela família e, a partir desse senso comum, a representação social que se teria do surdo é de "um ser incompleto, menor". A autora continua: "Não está em discussão o quanto ele pode escutar, se beneficiado por aparelhos de amplificação sonora, ou a partir de um trabalho educativo, a partir da utilização da Língua de Sinais Brasileira - Libras [...], o rótulo está dado, a imagem incorporada" (HAGUIARA-CERVELLINI, 2003, p. 53).

Neste sentido, Goffman (1988, p. 14) explica o estigma como um atributo depreciativo que atinge um indivíduo e confirma a normalidade do outro. Tal indivíduo não assume os papéis sociais prescritos dentro do que se aceita como normalidade. “Ele é um desviante e, portanto, indesejável” (GOFFMAN, 1988, p. 44).

Das respostas de ambas as professoras a respeito do estigma em seus ambientes de trabalho, podemos inferir algumas considerações. A professora Amanda relata que, em suas aulas, as crianças respeitam e ajudam o colega com deficiência intelectual. A professora Berenice, por sua vez, conta que escuta reclamações dos seus colegas professores e que percebe um certo ciúme das outras crianças em relação ao aluno com deficiência.

Acreditamos que esta diferença de tratamento com as crianças com deficiência está relacionada ao contexto onde estão inseridas. O aluno da professora Amanda está envolvido com dez crianças na aula de música, enquanto o aluno da professora Berenice tem 29 crianças para se relacionar. Além disso, a professora Amanda trabalha exclusivamente com música, em uma aula não formal, ou seja, que não pertence à matriz obrigatória do currículo escolar, enquanto a professora Berenice trabalha como segundo professor de uma turma na sala de aula regular. Sabemos que esta diferença de contexto e perspectivas não deveria modificar o tratamento em relação às crianças 
com deficiência, mas muitas vezes influencia as atitudes, tanto das crianças como dos adultos.

É possível identificar alguns outros fatores a respeito das relações entre alunos incluídos. Os alunos da professora Amanda, por estarem em menor quantidade, (são dez alunos, que tem aulas de violino em espaço extraclasse) têm maior possibilidade de estabelecer um diálogo e uma relação íntima com o aluno com deficiência, podendo observar tanto suas potencialidades como suas dificuldades. Dessa forma, pode-se concluir que não existem preconceitos em relação à criança com deficiência nas aulas de música da professora Amanda. Já os alunos da sala onde atua a professora Berenice têm dificuldades em compreender que existe diferença, mas que esta não altera a natureza do relacionamento entre eles. Consciente ou inconscientemente, criamos "padrões" sociais que esperamos que sejam seguidos, e para os alunos daquele grupo não seria diferente. Porém, a escola deve ser o lugar de tratar essas questões de maneira diferenciada, ou seja, como já anunciaram Booth e Ainscow (2011), envolve colocar valores em ação de modo a minimizar exclusões e/ou barreiras à aprendizagem e à participação de todo e qualquer indivíduo, valorizando-o diante da diversidade.

\section{COMENTÁRIOS CONCLUSIVOS}

Conforme as argumentações de Goffman (1988), é possível concluir que a sociedade necessita mudar os seus parâmetros, pois classifica as pessoas deficientes como diferentes. É preciso mudar esta prática, mas a mudança não pode ficar só no discurso. Como afirmam Valle e Connor (2014, p. 34), "podemos legislar políticas, mas não podemos legislar atitudes". Os autores ainda alegam:

Em uma sala de aula onde todos os estudantes são respeitados como alunos competentes e ativos - independentemente do nível de habilidade -, há um espaço para que todos aprendam e cresçam. Lembre-se: não se trata de incluir ou não alunos com deficiência em uma sala de aula de educação geral, mas como fazê-lo de forma efetiva. (VALLE; CONNOR, 2014, p. 91, grifos da autora). 
A opinião das professoras e sua relação com a literatura evidenciam que a inclusão ainda está em um momento de transformação e de análise de abordagens e perspectivas. Este quadro deve-se ao fato de as duas professoras atuarem em contextos inclusivos, no entanto, possuem diferenças relevantes nas suas experiências de inclusão. Apesar disso, foi possível perceber que ambas têm as suas motivações pessoais para trabalhar em contexto inclusivo e se preocupam com questões relacionadas ao ambiente educacional como um todo, muito além das ações para prover a inclusão com deficiência. De todo modo, ficou evidenciado nas práticas de sala de aula dessas professoras que elas buscaram incluir os alunos, mas, ainda, apesar dos esforços empreendidos, persistiu nas unidades escolares uma cultura na qual não se pode eliminar todos os preconceitos ou convenções presentes na sociedade, inclusive aqueles que pressupõem que alunos com deficiência intelectual pouco poderão aprender no espaço educativo.

Portanto, reconhecer a diferença é um recurso para garantir a participação de todos e o apoio à aprendizagem. De acordo com Booth e Ainscow (2005, p. 7): "A participação significa aprender junto com outros e colaborar com eles em experiências compartilhadas de aprendizagem". Isto requer um engajamento ativo com a aprendizagem e sobre como a inclusão é experienciada. Assim como as professoras Amanda e Berenice, acreditamos na inclusão das pessoas com deficiências no contexto escolar, na potencialidade transformadora dessa ação, nos valores, representações e crenças que podem ser aprendidos na e pela escola; valores esses que podem ser fundamentalmente importantes para que os deficientes sejam tratados com o respeito e a flexibilidade necessários para pôr em prática e envolver a todos no processo educativo inclusivo. 


\section{REFERÊNCIAS}

BRASIL. Ministério da Saúde. Conselho Nacional de Saúde. Resolução nº 466, de 12 de dezembro de 2012. Aprova as Diretrizes e normas regulamentadoras de pesquisas envolvendo seres humanos. Disponível em: http://bvsms.saude.gov.br/bvs/saudelegis/cns/ 2013/res0466_12_12_2012.html. Acesso em: 24 abr. 2019.

BOOTH, Tony; Mel AINSCOW. Index para a inclusão: desenvolvendo a aprendizagem e a participação na escola. 2. ed. Trad. Mônica Pereira dos Santos. Bristol: Unesco/CSIE, 2005.

BOOTH, T; AINSCOW, M. Index para Inclusão: desenvolvendo a aprendizagem e a participação na escola. Tradução: Mônica Pereira dos Santos. 3. ed. LaPEADE, Rio de Janeiro, 2011.

GIL, Antônio Carlos. Métodos e técnicas de Pesquisa Social. 6. ed. São Paulo: Atlas, 2008.

GOFFMAN, Ervin. A representação do eu na vida cotidiana. Trad. Maria Célia Santos Raposo. 3 ed. Petrópolis, RJ: Vozes, 1985.

GOFFMAN, Ervin. Estigma: notas sobre a manipulação da identidade deteriorada. Trad. Márcia Bandeira de Mello leite Nunes. 4. ed. Rio de Janeiro: Editora Guanabara S.A. 1988.

GOFFMAN, Ervin. Estigma: notas sobre a manipulação da identidade deteriorada. 4. ed. Rio de Janeiro: LTC, 2008.

GRAY, David E. Pesquisa no mundo real. 2a. ed. Porto Alegre: Penso, 2012.

HAGUIARA-CERVELLINI, Nadir. A musicalidade do surdo: representação e estigma. São Paulo: Plexus, 2003.

MARCONI, Marina de Andrade; LAKATOS, Eva Maria. Técnicas de pesquisa. 7. ed. São Paulo: Atlas, 2010.

MOSCOVICI, Serge. Representações sociais: investigações em psicologia social. Trad. Pedrinho A. Guareschi. 8. ed. Petrópolis, RJ: Vozes, 2011.

MOSCOVICl, Serge. A representação social da psicanálise. Trad. Álvaro Cabral. Rio de Janeiro: Zahar, 1978. 291p.

SANTA CATARINA. Resolução n 112. Fixa normas para a Educação Especial no Sistema Estadual de Educação de Santa Catarina. Florianópolis, 2006.

SANTA CATARINA. Lei $n^{\circ} 17.143$, de 15 de maio de 2017. Dispõe sobre a presença do Segundo Professor de Turma nas salas de aula das escolas de educação básica que integram o sistema estadual de educação de Santa Catarina. 2017. Disponível em: http:// leis.alesc.sc.gov.br/html/2017/17143_2017_lei.html. Acesso em: 28 fev. 2019.

SANTOS, Mônica Pereira dos et al. Desenvolvendo o Index para Inclusão no contexto brasileiro: experiências de reflexão/ação sobre processos de inclusão e exclusão em Educação. Percurso Acadêmico, Belo Horizonte, v. 7, n. 14, p. 332-350, jul./dez. 2017. 


\section{EDUCACÃO, ARTES E INCLUSÃO}

SANTOS, Mônica Pereira dos et al. O Index para Inclusão como instrumento de pesquisa: uma análise crítica. Rev. Bras. Ed. Esp., Marília, v. 20, n. 4, p. 485-496, out./dez. 2014.

SANTOS, Mônica Pereira dos. Index para inclusão. Ed. rev. Rio de Janeiro, set. 2002.

VALLE, Jan W.; CONNOR, David J. Ressignificando a deficiência: da abordagem social às práticas inclusivas na escola. Trad. Fernando de Siqueira Rodrigues. Porto Alegre: AMGH, 2014.

Recebido em 10 de maio de 2019 Aprovado em 19 de março de 2020 